\title{
Quantifying Oral- Sensory Issues in Children with Autism and studying its Association with Feeding Issues
}

\author{
Disha Rao* \\ Department of OTO, India \\ Submission: October 04, 2016; Published: March 22, 2017 \\ *Corresponding author: Disha Rao, Department of OTO, India, Email: disharao2993@gmail.com
}

\section{Introduction}

Autism is defined as a neurodevelopmental disorder which is characterized by repetitive behaviors, social withdrawal and communication deficits. It is defined as the second most common developmental disability after mental retardation, among children (Centres for Disease Control and Prevention, 2009). Edelson et. al (1999) has reported that children with autism have difficulty in managing the sensory input due to high arousal or anxiety level. They over react (hyper sensitivity) or under-react (hypo- sensitivity) to oral, tactile, visual \& aural input and result in imbalanced reaction which further results in difficulty to participate in typical life activities. This is known as sensory processing disorder. These sensory issues are associated with the feeding problems in children with autism (Nadon et. al, 2011).

The oral structures and their functions is a complex process. Oral development involves acquiring skills that are movementbased as well as sensory-based. Feeding requires mastery of oral abilities ie. lip jaw tongue co-ordination. Johnson (2008) studied the role of jaw on feeding and speech. He reported that the ability to move jaw, lips and tongue independently is a prerequisite for normal feeding, oral control and articulated speech. Jaw stability is required for production of speech and management of feeding. Assessment and treatment of jaw function provides additional understanding of a child's developmental abilities and how they use it to produce meaningful speech. Hence, jaw stability gives an idea of more complex movements for later developing speech sounds and co-articulation while also providing an understanding into a child's sensory system and compensatory patterns for speech and feeding. Hence, there is need to use a scale that can assess child's lip jaw-tongue differentiation at the time of evaluation to know about how much child is aware about his/her articulators and to even find out whether the awareness of articulators is related to the feeding habits of the child.

\section{Need For The Study}

As a speech and language pathologist, we do a complete evaluation however sometimes we miss out on sensory issues present in children with autism. Children with autism are less/ not aware about their articulators ie. have poor lip- jaw-tongue differentiation. It has been observed that children who are least/ not aware about their oral articulators have feeding issues. To the best of the researcher's knowledge, very few studies have addressed feeding and sensory issues in children with autism in the Indian context. Hence, this study was conducted to know if there is any association between sensory issues, awareness about the articulators and feeding issues.

\section{Aims and Objectives}

To quantify the oral sensory issues and its association with feeding were the specific objectives: To study the :

a) Performance of children diagnosed with autism having sensory issues on lip-jaw-tongue differentiation scale.

b) Performance on oral input defensiveness sub section of sensory processing disorder checklist

c) The relationship of lip-jaw-tongue differentiation score with that of awareness of articulators

d) The association between oral sensory issues, awareness of the articulators \& feeding issues.

\section{Methodology}

The present study was conducted in a private clinical set up in Mumbai. The participants included two groups of 10 children each in the age range 3-6 years. Group I included children with normal speech and language skills with no sensory and/or feeding issues who served as control group. Group II included 10 children diagnosed with ASD on DSM- V by psychiatrist and/ 
or pediatrician. All of them reportedly had sensory issues but no other medical issues. All participants belonged to middle socioeconomic status.

The procedure used was as follows:

i. Informed consent was taken

ii. Demographic details were obtained

iii. A detailed case history was taken followed by oral peripheral examination

iv. 'Lip- jaw differentiation scale' which is available and freely downloadable was administered on all the participants. It is a 3 point rating scale where in child is instructed to perform lip jaw tongue differentiation task (Score 3 - able to do oral movements with ease, 2- with difficulty \& 1- unable to do). Maximum obtainable score is 18 and Score < 12 s/o poor lip jaw tongue differentiation i.e. Reduced/no awareness of the articulators.

v. Section of oral input defensiveness from Sensory processing disorder checklist (Dunn) which is also available and freely downloadable was administered.

vi. The data was subjected to statistical analysis

\section{Results \& Discussion}

The scores on lip- jaw- tongue differentiation scale between Group I (control group) and Group II (Children diagnosed with autism) were analyzed using unpaired t- test. Mean for group I is 17.30 with SD of 0.67 and that of group II is 7.80 with SD of 0.79 . The two tailed $P$ value is less than 0.0001 . By conventional criteria, this difference is considered to be extremely statistically significant. This reveals that participants of group I showed better awareness on the lip-jaw-tongue differentiation scale than the participants of group II. Participants of group I scored between 15- 18 on the lip-jaw differentiation scale however participants of group II showed low scores i.e. between 7-9 $(<12)$.
The findings are consistent with the oral input defensiveness on the sensory processing disorder checklist where in the participants of group II demonstrated many sensory issues such as extreme food preferences, gagging for specific textured foods, dislike for mouthwash, licking of inedible objects, drooling, love for vibrating tooth brush suggesting that children with autism who fall below a score of 12 showed poor lip-jaw-tongue differentiation also demonstrated with feeding problems. They also preferred specific temperature and texture of food. This is in accordance with the findings of Marshall et al. (2013) who reported that feeding difficulties in form of undesirable mealtime behaviors and/or skill deficits caused parental concern, impact on family dynamic and poor nutrition which further had an impact on development and health outcome.

\section{Summary \& Conclusion}

Present study shows that children diagnosed with autism having sensory issues show poor performance (score < 12) on lip-jaw-tongue differentiation scale which is suggestive of least/no awareness of their articulators. These findings are consistent with the oral input defensiveness shown by the child on sensory processing disorder checklist. The study also shows that there is association between sensory issues, awareness of the articulators, and feeding issues. Hence, we conclude that, as a speech and language pathologist, we need to be aware about all the problems faced by children with autism. So a holistic evaluation of speech- language skills, sensory issues and feeding issues is a must. Feeding issues hamper their nutrition as well as their overall development in children with autism due to high arousal level and anxiety; they develop sensory issues and become very defensive to any external oral stimulus which is crucial for feeding. So, if their awareness of the various articulators and feeding issues are targeted by the SLP then it may be very helpful in effectively managing speech-language, sensory and feeding issues.

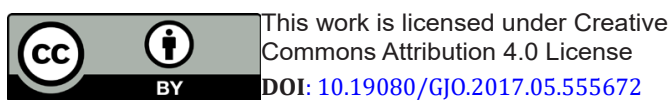

\section{Your next submission with Juniper Publishers will reach you the below assets}

- Quality Editorial service

- Swift Peer Review

- Reprints availability

- E-prints Service

- Manuscript Podcast for convenient understanding

- Global attainment for your research

- Manuscript accessibility in different formats

( Pdf, E-pub, Full Text, Audio)

- Unceasing customer service

Track the below URL for one-step submission https://juniperpublishers.com/online-submission.php 